\title{
Predominance of serum antibodies to synthetic peptide stemming from HPV 18 open reading frame $\mathrm{E} 2$ in cervical adenocarcinoma
}

\author{
M Lehtinen, A Leminen, J Paavonen, P Lehtovirta, H Hyöty, E Vesterinen, J Dillner
}

Institute of

University of

Tampere, POB 607,

33100 Tampere,

Finland

M Lehtinen

H Hyöty

Departments of

Obstetrics and

Gynecology, Helsinki

University Central

Hospital, Helsinki,

Finland

A Leminen

J Paavonen

P Lehtovirta

E Vesterinen

Department of

Institutet, Stockholm,

Sweden

J Dillner

Correspondence to:

Matti Lehtinen

Accepted for publication

1 November 1991
Biomedical Sciences,

Virology, Karolinska

\begin{abstract}
Aims To determine if there are type specific differences in serum antibody responses to synthetic peptides derived from human papillomavirus (HPV) open reading frame (ORF) $E 2$ in patients with cervical carcinoma.

Methods Diagnostic phase sera from 88 age-matched women with cervical adenocarcinoma (AC), cervical squamous cell carcinoma (SC), ovarian cancer $(\mathbf{O C})$ or no gynaecological malignancy were available. Serum IgG and IgA antibodies to synthetic peptides corresponding to a residue of HPV 6, 11, 16, and 18 ORF E2 18 amino acids long and a control peptide from mumps virus were determined by ELISA.
\end{abstract}

Results Both IgA and IgG antibody positivity to the HPV 18 peptide were associated with increased risk (9-0-fold, confidence limits 1.5-199) for AC. IgA positivity to HPV 11, 16, and 18 peptides was associated with an increased risk for SC. However, the association of IgG antibodies to HPV 16 peptide with SC was not significant. IgA or IgG antibodies to HPV 6 or mumps virus peptides were not associated with increased risk for $A C, S C$, or OC.

Conclusions These results suggest a specific role for HPV 18 in AC. Differences in antibody responses to HPV peptide in $A C$ and SC suggest immunopathogenetic

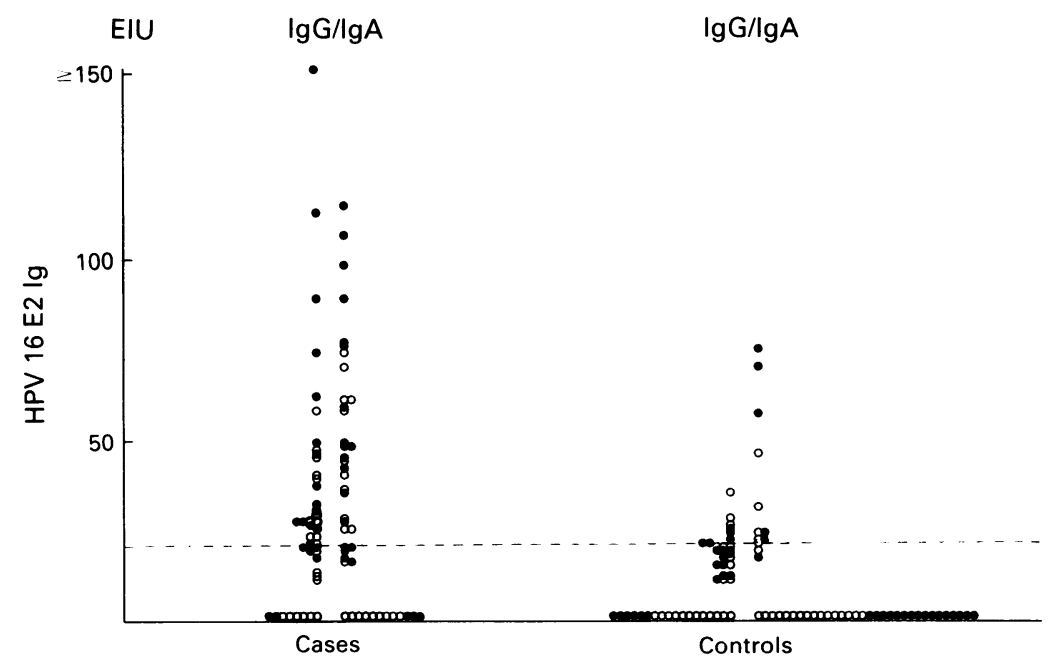

Figure 1 Ig A and IgG antibody levels to HPV 16 E2 peptide 245 in cervical carcinoma patients and their age-matched controls. Cases: $(O)$ patients with cervical adenocarcinoma ( $A C)$; (O) patients with cervical squamous cell carcinoma (SC). Controls: ( ) healthy women); ( ) patients with ovarian cancer. differences between the two types of cervical carcinoma.

The association of human papillomavirus (HPV) infection with cervical carcinoma is well documented, although the nature of the association may be different for different HPV types. ${ }^{12} \mathrm{HPV}$ type 16 is the most prevalent HPV type in squamous cell carcinoma (SC), while most of HPV DNA positive patients with cervical adenocarcinoma (AC) are positive for HPV 18 DNA. $^{3-5}$ Increased levels of serum antibodies to early HPV 16 proteins E2, E4, and E7 have been reported in patients with cervical carcinoma, but little emphasis has been paid to the histological types of the tumours. ${ }^{6-8}$ Synthetic peptide 245 derived from HPV 16 open reading frame (ORF) E2 has recently been introduced for testing serum antibodies to HPV. ${ }^{6}$ Serum antibody levels to the above peptide and to the corresponding peptides of HPV 6,11 , and 18 were determined in patients with $\mathrm{AC}$ and SC.

\section{Methods}

Twenty two consecutive patients with AC (mean age 53.7 years, range 26-81) were enrolled from the Departments of Obstetrics and Gynecology, Helsinki University Central Hospital, from 1988-1991. Twenty two agematched patients with SC (mean age 54.8 years, range 31-80) were also studied. Eighteen $(82 \%)$ of the patients with AC, and $14(64 \%)$ of the patients with SC represented early (I-II) stage carcinomas. Controls consisted of 22 agematched healthy women (mean age 52.5 years, range 25-79) admitted for elective surgery, and 22 patients with ovarian cancer (OC) (mean age 60.6 years, range $31-85$ ).

Peptide 245 is a synthetic peptide derived from HPV 16 ORF E2 ${ }^{9}$ consisting of 18 amino acids (HKSAIVTLTYDSEWQRDQ) originally described by Dillner et al. ${ }^{6}$ Corresponding peptides stemming from HPV 6 ORF E2 (HKHAIVTVTYDSEEQRQQ) ${ }^{10} \mathrm{HPV} 11$ ORF E2 (HKNAIVTLTYSSEEQRQQ), ${ }^{11}$ and 18 ORF E2 (EKTGILTVTYHSETQRTK) ${ }^{12}$ were synthesised as described. ${ }^{7}$ (Amino acids common to HPV 16 peptide 245 and other HPV types are underlined.) The HPV 16 peptide and a peptide (RFAKYQQQGRLEARC) derived from mumps virus nucleocapsid protein (amino acids 195-208) were purchased from Cambridge Research Biochemicals Ltd, UK. 


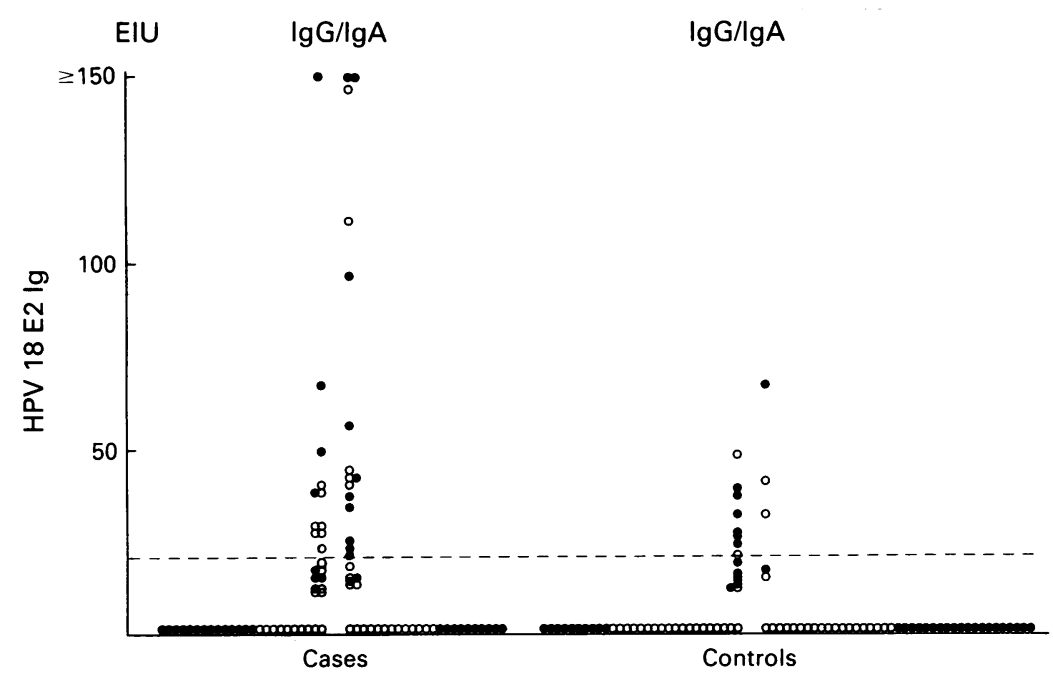

Figure 2 IgA and IgG antibody levels to HPV 18 E2 peptide 245 in cervical carcinoma patients and their age-matched controls. Cases: (O) patients with cervical adenocarcinoma ( $A C)$; (O) patients with cervical squamous cell carcinoma (SC). Controls: ( $\bigcirc)$ healthy women); ( ) patients with ovarian cancer.

IgA and IgG antibodies to the HPV E2 peptides 245 and to the mumps peptide were analysed by a three-step modification of enzyme-linked immunosorbent assay (ELISA), as previously described. ${ }^{6}$ Mumps virion antibodies were measured by ELISA using a purified virion antigen. ${ }^{13}$ Results were expressed in enzyme immunoassay units (EIU) which yield a background corrected percentage of the absorbance value of the positive reference serum. ${ }^{13}$ Positivity for IgG and IgA antibodies was defined as $>20$ EIU.

Relative risk and $95 \%$ confidence limits were calculated according to Breslow and Day. ${ }^{14}$

\section{Results}

Compared to controls, IgA antibody levels to the HPV 18 peptide were higher in patients with both AC and SC (fig 1), whereas IgA antibody levels to the HPV 16 peptide appeared to be increased mainly in patients

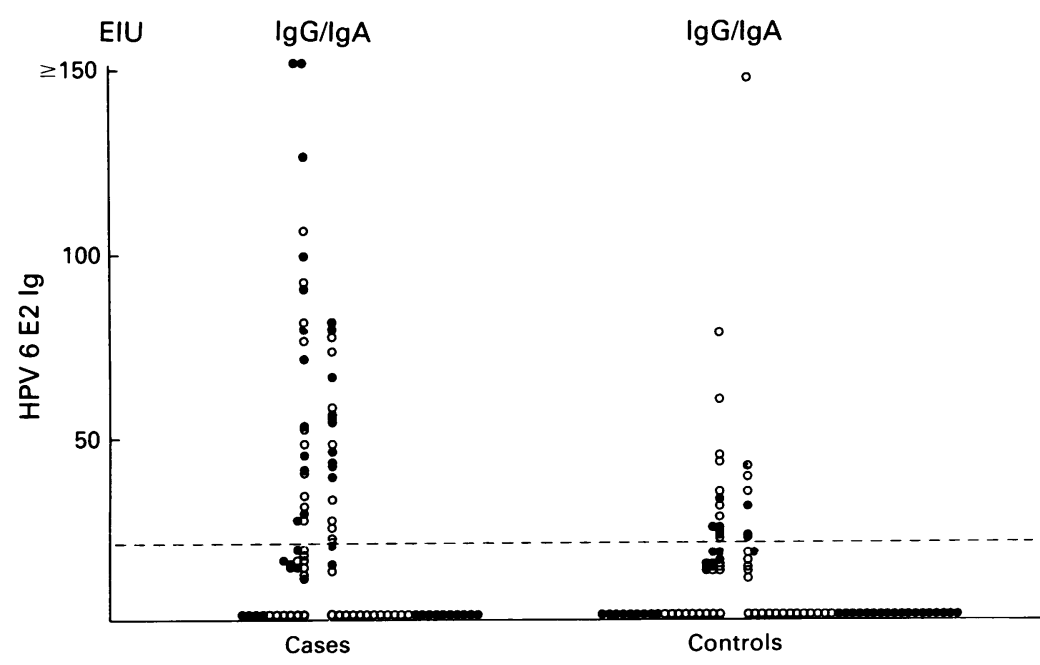

Figure 3 IgA and IgG antzbody levels to HPV 6 E2 peptide 245 in cervical carcinoma patients and their age-matched controls. Cases: (O) patients with cervical adenocarcinoma (AC); ( ) patients with cervical squamous cell carcinoma (SC). Controls: ( () healthy women); (O) patients with ovarian cancer. IgA and Ig $G$ antibody levels to HPV 11 E2 peptide 245 were essential similar (data not shown). with SC (fig 2). No such differences between patients and controls were found in $\operatorname{IgA}$ antibody levels to the HPV 6 (or HPV 11) peptide, or mumps peptide (or mumps virion antigen) (figs 3 and 4). IgA positivity for the HPV 18 peptide indicated an increased risk of AC whereas IgA positivity for the HPV 11, 16, and 18 peptides indicated an increased risk of SC (table). However, because of the small number of patients studied the exact magnitude of the risk could not be calculated for HPV 16 and 18 peptides. No significant risk ratios were found when HPV 6 or mumps IgA antipeptide antibody levels were compared between patients and controls (table). Furthermore, HPV IgA antipeptide antibodies did not indicate increased risk of OC.

IgG antibody levels to the HPV peptides were higher in patients with $\mathrm{AC}$ and $\mathrm{SC}$ than in controls (figs 1, 2, and 3). However, only HPV 18 IgG positivity indicated a statistically significant risk of AC. IgG positivity for the HPV 18 and 11 , but not for the HPV 16 peptide, indicated an increased risk of SC (table). IgG antibodies to HPV 6 (fig 3) or mumps virus (fig 4) peptides showed no increased risk of cancer.

Nine patients with SC and five patients with AC who had raised IgA antibody levels to the HPV 16 or HPV 18 peptide before treatment were monitored by serial antibody determinations (fig 5). In patients with SC the HPV 16 antibody levels rapidly decreased following surgical treatment whereas in patients with AC the HPV 18 antibody levels showed only gradual decrease. In five $(71 \%)$ of seven patients with advanced (III-IV) stage SC the antibody levels first decreased but subsequently increased (fig 5B).

\section{Discussion}

IgA and IgG antibody responses to synthetic peptides derived from HPV 6, 11, 16, and 18 ORF E2 were measured in patients with $\mathrm{AC}$ or SC, and in controls (patients with ovarian cancer or healthy women). Increased IgA and IgG antibody levels to the HPV 18 peptide indicated a significantly increased risk of AC. HPV 18 DNA has been linked to most ACs, ${ }^{3-5}$ although a recent study using in situ hybridisation challenged the association by arguing that the HPV DNA detected in AC by polymerase chain reaction (PCR) or Southern blot hybridisation is derived from squamous epithelium. ${ }^{15} \mathrm{HPV}$ DNA positive adenocarcinoma cells were, however, detected by in situ hybridisation in $18 \mathrm{AC}$ cases, $16(88 \%)$ of whom were positive of HPV $18 .^{5}$ The present findings further support the specific role for HPV 18 in AC.

Assessment of the relative risk of SC associated with HPV 16 or 18 IgA positivity was not possible. A larger sample showed that IgA antibody positivity to the HPV 16 peptide indicated a 13-fold risk of SC (Lehtinen et al, unpublished results).

HPV 18 and 11 IgG antipeptide antibodies showed an increased risk for SC. Patients with HPV 16 antipeptide antibodies have been shown by immunoblotting to have antibodies 


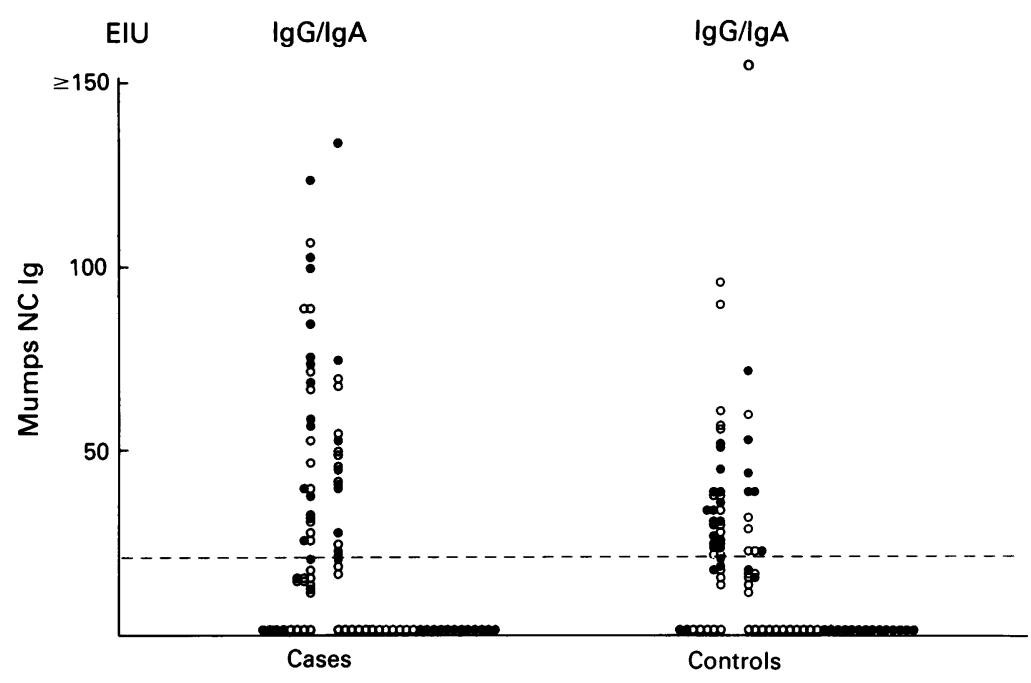

Figure 4 IgA and IgG antibody levels to peptide derived from mumps virus nucleocapsid protein in cervical carcinoma patients and their age-matched controls. Cases: (O) patients with cervical adenocarcinoma $(A C) ;(\mathbf{O})$ patients with cervical squamous cell carcinoma (SC). Controls: (O) healthy women); (О) patients with ovarian cancer. IgA and IgG antibody levels to mumps virion antigens were essentially similar (data not shown).

to HPV $16 \mathrm{E} 2 .^{6}$ It is difficult to explain why serum IgG antibodies to the HPV 16 peptide were not associated with increased risk of SC. The low risk of SC associated with HPV 16 IgG positivity was about the same as that described by Mann et $a l^{16}$ and similar to our findings in the larger sample (Lehtinen et al, unpublished results). The difference between HPV 16 and 18 (HPV 11) may be a chance observation or may reflect a difference in the IgG antibody response to HPV 16 and 18 in SC. An undefined cross-reactivity between HPV 18 and HPV 11 peptides seems to exist.

Post-treatment changes in serum HPV 16 IgA antibody levels in patients with SC were faster compared to the more gradual decrease of HPV 18 E2 IgA antibody levels seen in patients with AC. Because IgA has a relatively short half-life HPV E2 protein must be present in cervical tissue to elicit IgA antibody response in patients with SC. While HPV E2 RNA and protein are abundantly expressed during cervical HPV infection or HPV-associated

Table Relative risk (95\% confidence limits) of cancer indicated by $\operatorname{Ig} A$ or $\operatorname{IgG}$ antibody positivity to peptide 245 derived from HPV ORF E2 in patients with cervical adenocarcinoma $(A C, 22)$, cervical squamous cell carcinoma (SC, 22), and ovarian cancer $(O C, 22)$ compared to their age-matched healthy controls (22)

\begin{tabular}{|c|c|c|c|}
\hline \multirow[b]{2}{*}{ Category } & \multicolumn{3}{|l|}{ Relative risk } \\
\hline & $A C$ & $S C$ & $O C$ \\
\hline $\begin{array}{l}\text { HPV } 6 \mathrm{IgA} \\
\text { HPV } 11 \mathrm{IgA} \\
\text { HPV } 16 \mathrm{IgA} \\
\text { HPV } 18 \mathrm{IgA} \\
\text { Mumps NC }+\mathrm{IgA} \\
\text { Mumps virion IgA }\end{array}$ & $\begin{array}{ll}3.5 & (0.8-23.3) \\
6.0 & (0.9-135) \\
4.0 & (0.5-90 \cdot 0) \\
9.0 & (1.5-199)^{\star} \\
2.0 & (0.414 .8) \\
2.0 & (0.2-57.8)\end{array}$ & $\begin{array}{ll}4 \cdot 0 & (1 \cdot 0-26 \cdot 0) \\
5.5 & (1 \cdot 4-34 \cdot 6)^{\star} \\
\infty & (1 \cdot 9-\infty)^{\star} \\
\infty & (2 \cdot 9-\infty)^{\star} \\
1 \cdot 5 & (0 \cdot 4-11 \cdot 3) \\
1.5 & (0 \cdot 2-12 \cdot 1)\end{array}$ & $\begin{array}{ll}0.8 & (0 \cdot 2-3 \cdot 4) \\
1 \cdot 0 & (0.3-3 \cdot 5) \\
0.5 & (0.0-6 \cdot 4) \\
1 \cdot 3 & (0 \cdot 2-6 \cdot 7) \\
1.0 & (0 \cdot 2-5 \cdot 4) \\
1.0 & (0 \cdot 1-37 \cdot 5)\end{array}$ \\
\hline $\begin{array}{l}\text { HPV } 6 \mathrm{IgG} \\
\text { HPV } 11 \mathrm{IgG} \\
\text { HPV } 16 \mathrm{IgG} \\
\text { HPV } 18 \mathrm{IgG} \\
\text { Mumps NC+ IgG } \\
\text { Mumps virion IgG }\end{array}$ & $\begin{array}{ll}2 \cdot 0 & (0.5-9.0) \\
5 \cdot 0 & (0 \cdot 7-90 \cdot 9) \\
6.0 & (0.9-135) \\
9.0 & (1.5-199)^{\star} \\
1.0 & (0.3-3.3) \\
1.0 & (0 \cdot 1-9 \cdot 2)\end{array}$ & $\begin{array}{ll}3.0 & (0 \cdot 7-17 \cdot 5) \\
5.0 & (1 \cdot 3-31.8)^{\star} \\
2.0 & (0 \cdot 4-14 \cdot 9) \\
\infty & (1.9-\infty)^{\star} \\
2.3 & (0.6-10.4) \\
1.5 & (0 \cdot 2-12 \cdot 1)\end{array}$ & $\begin{array}{ll}0.4 & (0.1-1.9) \\
1.7 & (0.5-8.0) \\
5.0 & (0.7-110) \\
1.5 & (0.2-12.0) \\
2.8 & (1.0-11.5) \\
\text { Not available }\end{array}$ \\
\hline
\end{tabular}

*Statistically significant.

†Peptide (RFAKYQQQGRLEAR-C) is derived from mumps virus nuclecapsid protein (amino

acids 195-208).

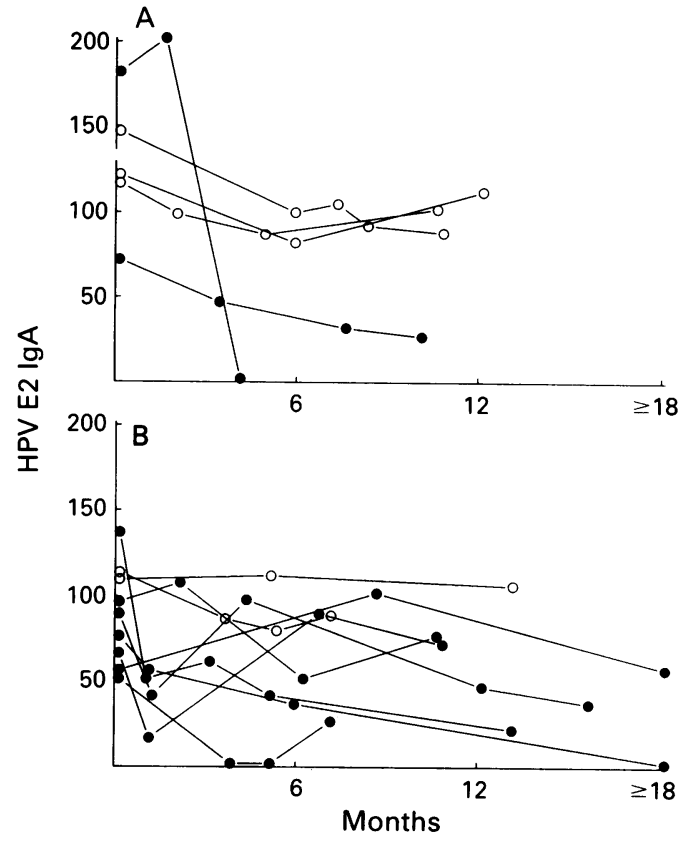

Figure 5 Serum Ig $A$ antipeptide antibody response to $H P V E 2$ in (O) five patients patients with cervical adenocarcinoma (HPV $18 \mathrm{E2}$ peptide 245) and (O) nine patients with cervical squamous cell carcinoma (HPV 16 E2 peptide 245) (A) early (I-II) stage carcinomas; (B) advanced (III-IV) stage carcinomas.

cervical intraepithelial neoplasia ${ }^{61718}$ integration of HPV DNA (especially HPV 18 DNA) might inhibit the expression of the $\mathrm{E} 2$ gene in cervical carcinoma. ${ }^{1920}$ However, episomal HPV 16 and E2 mRNA are often seen in SC..$^{19}$ It is also possible (especially for HPV 18) that the $\mathrm{E} 2$ protein is expressed in cervical tissues adjacent to the tumour but not in the tumour itself. This is similar to the system in EpsteinBarr virus (EBV) where serum antibodies to EBV early antigen are regularly increased in Burkitt's lymphoma. ${ }^{21} \mathrm{EBV}$ early antigens are expressed in EBV replicative sites but not in the EBV positive tumour itself.

The nature of HPV 16 and HPV 18 E2 expression and serum antibody responses to the E2 protein in patients with cervical carcinoma warrants further investigation.

1 Munoz N, Bosh X, Kaldor JM. Does human papillomavirus cause cervical cancer? The state of the epidemiological evidence. Br J Cancer 1988;57:1-5.

2 zur Hausen $H$. Papillomaviruses in anogenital cancer as a model to understand the role of viruses in human cancers. Cancer Res 1989;49:4677-81.

3 Cone R, Beckman A, Galloway D, Paavonen J. HPV typing of cervical adenocarcinomas by PCR. J Cell Biochem 1989;(suppl 13)C: 183.

4 Okakagi T, Tase T, Twiggs LB, Carlson L. Histogenesis of cervical adenocarcinoma with reference of human papillomavirus-18 as a carcinogen. J Reprod Med 1989; papilloma

5 Leminen A, Paavonen J, Vesterinen E, et al. Human papillomavirus types 16 and 18 in adenocarcinoma of the papillomavirus types 16 and 18 in adenocarcinom
uterine cervix. Am J Clin Pathol 1991;95:647-52.

6 Dillner J, Dillner L, Robb J, et al. A synthetic peptide Dillner J, Dillner L, Robb J, et al. A synthetic peptide
defines a serologic IgA response to a human papillomavirus-encoded nuclear antigen expressed in virus-carrying cervical neoplasia. Proc Natl Acad Sci USA 1989;86: $3838-41$.

7 Dillner J. Mapping of linear epitope of tissue papilloma virus type 16: the E1, E2, E4, E5, E6 and E7 open reading frames. Int J Cancer 1990;46:703-11.

8 Köchel HG, Monazahian M, Sievert K, et al. Occurrence of antibodies to $\mathrm{L} 1, \mathrm{~L} 2, \mathrm{E4}$, and $\mathrm{E} 7$ gene products of human papillomavirus types $6 \mathrm{~b}, 16$, and 18 among cervical cancer patients and controls. Int J Cancer 1991;48:682-8. 
9 Seedorf K, Krämmer G, Dürst M, et al. Hüuman papillomavirus type 16 DNA sequence. Virology 1985;145:181-5.

10 Schwarz E, Dürst M, Demankowski C, et al. DNA sequence and genome organization of genital human papillomavirus type 6b. Eur Mol Biol Org J 1983;12:2341-8.

11 Dartman K, Schwarz E, Gissman L, zur Hausen H. The nucleotide sequence and genome organization of human papillomavirus type 11. Virology 1986;151:124-30.

12 Cole ST, Danos O. Nucleotide sequence and comparative analysis of the human papillomavirus type 18 genome. Phylogeny of papillomaviruses and repeated structure of E6 and E7 gene products. J Mol Biol 1987;193:599-608.

13 Hyöty $H$, Huupponen T, Leinikki P. Humoral immunity against viral antigen in insulin dependent diabetes mellitus: altered IgA class immune response against mumps virus. Clin Exp Immunol 1985;60:1239-44.

14 Breslow N, Day N. Statistical methods in cancer research. The analysis of case control studies. IARC Scientific
The Publication no 32. Lyon: IARC, 1990.

15 Young FI, Ward LM, Brown LJR. Absence of human papilloma virus in cervical adenocarcinoma determined by in situ hybridization. J Clin Pathol 1991;44:340-1.

16 Mann VM, DeLao SL, Brenes M, et al. Occurrence of IgG and IgA antibodies to select peptides representing human papillomavirus type 16 among cervical cancer cases and papillomavirus type 16 among cervical

17 Crum CP, Sympula M, Ward BE. Topography of early HPV 16 transcription in high-grade genital precancers. $A m ~ J$ Pathol 1989;134:1183-8.

$18 \mathrm{Li} \mathrm{C-C} \mathrm{H,} \mathrm{Gilden} \mathrm{RV,} \mathrm{Showalter} \mathrm{SD,} \mathrm{Shah} \mathrm{KV.} \mathrm{Identifica-}$ tion of the human papillomavirus E2 protein in genital tract tissues. J Virol 1988;62:606-9.

19 Cullen AP, Reid R, Campion M, Lorincz AT. Analysis of the physical stage of different human papillomavirus DNAs in intraepithelial and invasive cervical neoplasias. $J$ Virol 1991;65:606-12.

20 Stoler M, Rodes C, Whitbeck A, et al. Gene expression of HPV types 16 and 18 in cervical neoplasia. UCLA Mol Cell Biol 1990;124:1-11.

21 Biggard RJ, Nkrumah FK, Henle W, Levine PH. Very late relapses in patients with Burkitt's lymphoma: clinical and serologic studies. JNCI 1981;66:439-44. 